\title{
Laparoscopic Surgery for Inflammatory Bowel Disease
}

\author{
Sergio Casillas Conor P. Delaney \\ Department of Colorectal Surgery and Minimally Invasive Surgery Center, Cleveland Clinic Foundation, \\ Cleveland, Ohio, USA
}

\section{Key Words}

Laparoscopic surgery • Inflammatory bowel disease •

Colitis, acute $\cdot$ Crohn's disease

\begin{abstract}
Laparoscopic surgery has recently been gaining acceptance as an alternative approach for patients with inflammatory bowel disease. There is increasing evidence demonstrating the multiple potential benefits of laparoscopy including faster recovery, reduced costs, and lower morbidity. For patients with acute colitis, a laparoscopic subtotal colectomy and end ileostomy have been shown to be feasible and safe in experienced hands. When indicated, many of these patients may be able to safely undergo a subsequent laparoscopic approach for construction of an ileo-anal pouch. Although still controversial, an elective laparoscopic restorative proctocolectomy with ileo-anal pouch anastomosis has also been shown to be feasible with functional outcomes at least similar to those obtained with an open approach. However, larger randomized series of patients are needed with longer follow-up in order to draw definite conclusions. For Crohn's disease, a laparoscopic approach is ideal for stoma creation. In addition, laparoscopic ileocolectomy is arguably the preferred approach for patients with terminal ileal disease. Some experienced lap-
\end{abstract}

aroscopic groups have also applied laparoscopic techniques for more complicated cases with recurrent disease or disease-related complications, such as fistulous disease. Other short-term benefits of a laparoscopic approach may include a decreased incidence of ventral hernias, decreased incidence of small bowel obstruction, and faster recovery. These benefits may also have significant economic impact. In contrast to earlier reports, there is reliable evidence that conversion is not associated with a poorer outcome. A policy of starting most suitable cases laparoscopically may offer patients the potential benefits of a laparoscopic approach without increasing morbidity.

Copyright $\odot 2005$ S. Karger AG, Basel

\section{Introduction}

Over the last few years, laparoscopic techniques have rapidly been gaining acceptance for the management of a wide variety of gastrointestinal pathology. Despite some controversy in the early 1990s [1, 2], there is now more convincing evidence of the multiple potential benefits of a laparoscopic colectomy (LAC): smaller incision size leads to improved cosmesis; reduced postoperative pain; earlier return of gastrointestinal function, and earlier tolerance to diet [3]. These factors contribute to a faster re-

\section{KARGER \\ Fax +41613061234 E-Mail karger@karger.ch} www.karger.com
C 2005 S. Karger AG, Basel 0253-4886/05/0223-0135\$22.00/0

Accessible online at: www.karger.com/dsu
Conor P. Delaney, MD, $\mathrm{PhD}$

Department of Colorectal Surgery

University Hospitals of Cleveland, 11100 Euclid Avenue

Cleveland, OH 44106 (USA)

Tel. +1 216844 7981, Fax +1 216844 8201, E-Mail conordel@aol.com 
Table 1. Laparoscopic or open subtotal colectomy (STC) for acute colitis

\begin{tabular}{lllllll}
\hline Reference & STC & Patients & $\begin{array}{l}\text { OR times } \\
\text { min }\end{array}$ & $\begin{array}{l}\text { LOS } \\
\text { days }\end{array}$ & Morbidity & $\begin{array}{l}\text { Subsequent } \\
\text { IPAA }\end{array}$ \\
\hline Dunker et al. [18], 2000 & laparoscopic & 10 & $271^{*}$ & $14.6^{*}$ & $30 \%$ & 6 \\
& open & 32 & 150 & 18 & $28 \%$ & 15 \\
Marcello et al. [16], 2001 & laparoscopic & 19 & $210^{*}$ & $4^{*}$ & $16 \%$ & 13 \\
Bell and Seymour [17], 2002 & open & 29 & 120 & 6 & $24 \%$ & N/A \\
& laparoscopic & 18 & 244 & $5^{*}$ & $33 \%$ & 17 \\
& open & 6 & N/A & 8 & N/A & 5 \\
\hline
\end{tabular}

OR = Operation; $\mathrm{LOS}=$ length of stay; IPAA = ileal pouch-anal anastomosis; N/A = data not available.

* Statistically significant.

covery of the patient (compared to similar open operations) with a reduced utilization of hospital resources, reduced costs, and earlier return of the patient to normal activity $[4,5]$.

The surgical literature relating to the application of laparoscopic techniques to patients with inflammatory bowel disease (IBD) is also slowly increasing. Early reports demonstrated the feasibility of laparoscopic surgery for the creation of stomas and for limited segmental disease [6]. This experience has evolved to more complex procedures ranging from ileo-cecectomy or subtotal colectomy (STC) for Crohn's disease (CD), to restorative proctocolectomy and ileal-anal pouch anastomosis (IPAA) for selected patients with ulcerative colitis (UC) or indeterminate colitis. In selected cases, these indications have even been expanded to patients requiring a STC for acute colitis.

Despite this growing body of evidence, a considerable number of IBD patients may be a formidable challenge even for the most experienced laparoscopic surgeon, and even more so to surgeons who do not operate frequently on patients with IBD. CD was the second most common diagnosis (preceded by diverticulitis) in a series of 51 patients requiring conversion at the Cleveland Clinic [7]. Other authors have reported similar results [8]. In addition, in certain cases, and despite the extensive preoperative work-up, which is often necessary in these patients, the surgeon has to be prepared to deal with unexpected findings that may require additional surgery. These include proximal strictures, fistulas, abscesses, or phlegmons. Unexpected proximal strictures were identified in about $20 \%$ of patients in a recent series of patients with $\mathrm{CD}$ undergoing a laparoscopic ileo-colectomy [9].
This article reviews the current status of laparoscopic surgery for IBD and addresses some issues that have prevented a more generalized acceptance of LAC for IBD, including costs, length of stay (LOS), and quality of life after surgery.

\section{Ulcerative Colitis}

Approximately $35 \%$ of patients with UC will eventually require colectomy [10]. There is a well-established spectrum of indications for surgery that ranges from acute toxic colitis to medical intractability, and dysplasia or cancer. In the acute setting, STC and end ileostomy have been shown to be the safest initial operation [11]. This can be followed in an elective setting by restorative proctocolectomy with or without temporary diversion, or total proctocolectomy and end ileostomy. Recently, laparoscopic surgery has been used in both acute and elective settings (table 1,2).

\section{STC and End Ileostomy}

In a review of the Cleveland Clinic IBD registry, fulminant disease occurred in $12.7 \%$ of patients with UC and was the second most frequent indication for surgery in UC [12]. The morbidity of surgery in this circumstance can be significant, in the order of 40-70\% [13]. The labile condition of the patient, frequently associated with considerable malnourishment and immunosuppression, was the initial concern for the performance of a laparoscopic STC. As more experience with LAC has been gathered, this argument is probably now one of the most appealing reasons for the application of minimally invasive, less traumatic techniques in this setting [14]. In addition, in 
Table 2. Laparoscopic or open restorative proctocolectomy and ileal pouch-anal anastomosis (IPAA)

\begin{tabular}{|c|c|c|c|c|c|c|}
\hline Reference & IPAA & Patients & $\begin{array}{l}\text { OR time } \\
\text { min }\end{array}$ & Diversion & $\begin{array}{l}\text { LOS } \\
\text { days }\end{array}$ & $\begin{array}{l}\text { Morbidity } \\
\%\end{array}$ \\
\hline \multirow[t]{2}{*}{ Marcello et al. [24], 2001} & laparoscopic & 20 & $330 *$ & 12 & $7 *$ & 20 \\
\hline & open & 20 & 230 & 20 & 8 & 25 \\
\hline \multirow[t]{2}{*}{ Dunker et al. [22], 2001} & laparoscopic & 16 & $292 *$ & N/A & $9 *$ & 11 \\
\hline & open & 19 & 159 & & 12 & 20 \\
\hline \multirow[t]{2}{*}{ Brown et al. [21], 2001} & laparoscopic & 12 & $150 *$ & 12 & 7.5 & 17 \\
\hline & open & 8 & 120 & 8 & 8 & 25 \\
\hline Ky et al. [23], 2001 & laparoscopic & 32 & 315 & 0 & 6 & 29 \\
\hline \multirow[t]{2}{*}{ Kienle et al. [20], 2003} & laparoscopic & 59 & 320 & 24 & 15 & 33.9 \\
\hline & open & 5 & & & & \\
\hline \multirow[t]{2}{*}{ Maartense et al. [27], 2004} & hand-assist & 30 & $210 *$ & N/A & 10 & 17 \\
\hline & open & 30 & 133 & & 11 & 13 \\
\hline
\end{tabular}

$\mathrm{OR}=$ Operation; $\mathrm{LOS}=$ length of stay; N/A = data not available or not relevant.

* Statistically significant.

experienced hands, the incidence of infectious complications, incisional hernia, and postoperative small bowel obstruction may be reduced [15].

With some variations in the surgical technique, the laparoscopic approach generally involves complete intracorporeal vascular ligation followed by mobilization of the colon to the rectosigmoid junction where the bowel is transected. Extraction of the specimen is performed through a left lower quadrant, midline, or Pfannenstiel muscle-splitting incisions, followed by creation of an end ileostomy and tacking of the rectal stump to the anterior abdominal wall. Marcello et al. [16] have reported 19 patients (16 with UC, 3 with CD) undergoing laparoscopic STC for acute colitis and matched them with a similar group of open colectomy patients. There was no difference in operative parameters, outcome, or morbidity between groups. Operative times were longer (by $90 \mathrm{~min}$ ) for the laparoscopic approach. However, laparoscopic STC patients had a shorter time for return of bowel function (median 1 vs. 2 days) and LOS (median 4 vs. 6 days). Subsequently, 13 of the 16 patients with UC underwent a successful laparoscopic restorative proctocolectomy and IPAA. Bell and Seymour [17] and Dunker et al. [18] have reported similar results in smaller series of patients (table 1).

With this initial experience, it is reasonable to conclude that laparoscopic STC for acute colitis has been proven feasible with results that appear equivalent to those obtained after open STC. Larger series of patients are needed to be able to draw more definite conclusions.
In addition, because of the technical challenge inherent with the acute colitis condition, it is recommended that only surgeons with significant expertise in laparoscopic bowel surgery and who are well beyond any learning curve perform this procedure.

\section{Restorative Proctocolectomy and IPAA}

The ileal pouch-anal anastomosis was described 20 years ago as a means of providing continence for patients who required removal of the colon and rectum. Since that time, IPAA has gained wide acceptance and has become the gold standard for the surgical treatment of patients with UC and familial adenomatous polyposis. IPAA maintains continence with satisfactory functional outcome, good quality of life and excellent patient satisfaction [19]. In a recent study from our institution, the functional outcome and quality of life after IPAA were analyzed in 1,895 patients [19]. Patients were stratified by age $(<45,45-55,55-65$ and $>65$ years), and outcomes were assessed prospectively at $1,3,5$, and 10 years after surgery. There were minor differences in the quality of life, health, energy, and satisfaction after surgery between age groups with a slight benefit for those under 45 years. Ninety-six percent of patients were happy to have undergone their surgery, and 98\% recommended it to others.

Laparoscopic restorative proctocolectomy with ilealpouch-anal anastomosis (LIPAA) has recently been used as an alternative to conventional open techniques. The possible advantages of a laparoscopic approach are a quicker recovery, potentially lower incidence of small 
bowel obstruction and other morbidities, and superior cosmetic results. There are now several reports assessing the feasibility and outcomes after a LIPAA in small series of patients [20-24]. The operation usually involves complete laparoscopic mobilization of the colon with intracorporeal vascular ligation, followed by exteriorization of the bowel through a Pfannenstiel incision. Proctectomy and creation of an IPAA with or without diversion is then performed as in the open approach. Some surgeons have increasingly utilized hand-assisted laparoscopic surgery for the performance of $\operatorname{LAC}[25,26]$. Although the concept is attractive and may facilitate intracorporeal dissection (especially of the transverse colon), hand-assisted laparoscopic surgery also increases the costs of an already expensive operation, and prospective randomized data are necessary to demonstrate the benefits of such an approach.

The largest reported experience for LIPAA comes from the University of Heidelberg in Germany [20]. Fifty-nine patients with UC and familial adenomatous polyposis were included in a prospective cohort study. Median operative time was 320 (210-690) min; median blood loss was $500 \mathrm{ml}$ with $27 \%$ of patients requiring transfusions. All patients had transanal mucosectomy and a hand-sewn anastomosis. Median LOS was 15 days and complications occurred in 33\% of patients (18\% major). Increased body mass index was a significant factor for conversion and postoperative complications. Conversion was also associated with an increase in perioperative morbidity and was related with poorer postoperative outcome.

Dunker et al. [22] reported the outcome and quality of life of 16 patients undergoing laparoscopic IPAA, and matched these to 19 open cases. Patient satisfaction and recovery time were better in the laparoscopic group (9.9 vs. 12.5 days). Morbidity was low and similar between groups. Operative times were significantly higher in the LIPAA patients (292 vs. $160 \mathrm{~min}$ ). However, the functional outcome (number of stools, soiling, incontinence, sexual activity), and quality of life were not different between groups. Marcello et al. [24] reported shorter LOS after LIPAA. In this study, 20 consecutive LIPAA patients were matched to a similar number of open cases. Median LOS was 7 days ( 8 days for the open group, $p=$ 0.02), 6 days for those diverted, and complications occurred in $20 \%$ of patients with no re-operations reported. Again, operative times were $1.5 \mathrm{~h}$ longer for the LIPAA group.

Randomized data have just been released comparing hand-assist and open proctocolectomy and ileal IPAA
[27]. Maartense et al. [27] reported a randomized controlled trial comparing a hand-port placed through an 8$\mathrm{cm}$ Pfannenstiel incision with those of open surgery through a midline incision. Body mass index was very low at approximately 23 per group. There was no difference in function and quality of life between groups, however, operating times were $80 \mathrm{~min}$ longer in the laparoscopic group $(\mathrm{p}<0.001)$. Morbidity and hospital stay were similar between groups, however, laparoscopic cases spent approximately USD 4,000 more per case during their inhospital stay $(p=0.05)$. The authors commented that the procedure is safe, but more expensive.

The need for a protecting stoma after IPAA also remains controversial. Clearly, there is a role for diversion in malnourished patients or in those who have required preoperatively considerable immunosuppression or a high dose of steroids. However, there is no clear-cut indication for 'healthier' patients. Similarly, patients who undergo transanal mucosectomy and hand-sewn anastomosis may benefit from a proximal stoma. Ky et al. [23] reported a series of 32 patients who underwent a one-stage LIPAA. There were 11 postoperative complications and 3 patients required re-operation. Median LOS was 6 days with a reported return of bowel function of 4.4 days. Although functional outcome was not formally assessed, only 1 patient was reported to have some degree of incontinence 2 months after surgery requiring the use of pads. The median number of stools was 7/day. Despite these encouraging feasibility data, these results do not yet approach those obtained after fast-track postoperative protocols with early diet and ambulation applied to patients undergoing open surgery [28]. A larger prospective study is needed in order to better validate the potential improvements in costs, LOS, and ultimate long-term outcomes for patients undergoing LIPAA.

\section{Crohn's Disease}

Despite the fact that laparoscopic techniques have been applied to patients with CD since the early 1990s, this approach has not been broadly accepted. The oftenassociated inflammatory adhesions and phlegmon may present significant technical challenges to the operating surgeon. The disease-related complications can also significantly increase the operative times and conversion rates, thereby limiting the overall utility of laparoscopic surgery in some cases. Nevertheless, LAC seems an appropriate alternative for a substantial number of patients with $\mathrm{CD}$. In fact, the disease affects a predominantly 
Table 3. Laparoscopic or open surgery for Crohn's disease

\begin{tabular}{|c|c|c|c|c|c|c|c|}
\hline Reference & Operation & Patients & $\begin{array}{l}\text { Conversion } \\
\% \mathrm{n}\end{array}$ & $\begin{array}{l}\text { OR time } \\
\text { min }\end{array}$ & $\begin{array}{l}\text { LOS } \\
\text { days }\end{array}$ & $\begin{array}{l}\text { Costs } \\
\text { USD }\end{array}$ & $\begin{array}{l}\text { Morbidity } \\
\%\end{array}$ \\
\hline \multirow[t]{2}{*}{ Wu et al. [38], 1997} & laparoscopic & 46 & 11 & $146^{*}$ & $4.4^{*}$ & \multirow[t]{2}{*}{ N/A } & $7 *$ \\
\hline & open & 70 & N/A & 202 & 7.9 & & 21 \\
\hline \multirow[t]{2}{*}{ Young-Fadok et al. [35], 2001} & laparoscopic & 33 & 5.9 & $147^{*}$ & $4 *$ & \multirow{2}{*}{$\begin{array}{l}8,648^{*} \\
11,673\end{array}$} & \multirow[t]{2}{*}{ NS } \\
\hline & open & 33 & N/A & 125 & 7 & & \\
\hline \multirow[t]{2}{*}{ Milsom et al. [36], 2001} & laparoscopic & 31 & 6.4 & $140 *$ & 5 & \multirow[t]{2}{*}{ N/A } & $16^{*}$ \\
\hline & open & 29 & N/A & 85 & 6 & & 27 \\
\hline \multirow[t]{2}{*}{ Duepree et al. [9], 2002} & laparoscopic & 21 & 4.8 & $75^{*}$ & $3 *$ & \multirow{2}{*}{$\begin{array}{l}2,547^{*} \\
2,985\end{array}$} & 14 \\
\hline & open & 24 & N/A & 98 & 5 & & 16 \\
\hline \multirow[t]{2}{*}{ Shore et al. [34], 2003} & laparoscopic & 20 & 5 & 145 & $4.25^{*}$ & \multirow{2}{*}{$\begin{array}{l}9,614^{*} \\
17,079\end{array}$} & 5 \\
\hline & open & 20 & N/A & 133 & 8.25 & & 0 \\
\hline \multirow[t]{2}{*}{ Hasegawa et al. [39], 2003} & laparoscopic & 54 & 10 & $200 *$ & 8 & \multirow[t]{2}{*}{ N/A } & 13 \\
\hline & open & 7 & N/A & 1260 & 8 & & 18 \\
\hline \multirow[t]{2}{*}{ Benoist et al. [33], 2003} & laparoscopic & 24 & 17 & 179 & 8 & \multirow[t]{2}{*}{ N/A } & 10 \\
\hline & open & 32 & N/A & 182 & 7.7 & & 20 \\
\hline
\end{tabular}

OR = Operation; LOS = length of stay; USD = US dollars; N/A = Data not available or not relevant; NS = not significant.

* Statistically significant.

young group of patients who are likely to require re-resection in $39-75 \%$ of cases [29].

In $\mathrm{CD}$, the most common laparoscopic operations include: stoma creation (colostomy or ileostomy), ileo-colic resection, small bowel resection or/and strictureplasty, segmental colectomy, and STC with/without ileo-rectal anastomosis (table 3).

\section{Stoma Creation}

This is one of the earliest indications for the use of minimally invasive techniques [5]. In cases of uncontrolled perineal sepsis or complex or persistent anal fistulas, laparoscopic fecal diversion (loop colostomy or loop ileostomy), coupled with adequate drainage of any anal infection, is a valuable and simple procedure. The simplicity of the operation, usually requiring only three $5-\mathrm{mm}$ ports, allows rapid recovery along with resolution of the acute septic process. In some cases it may also help as a bridge for the creation of a more definitive stoma. Patients recover quickly with no significant wound and their LOS in the hospital becomes limited only by their ability to learn how to manage the stoma [30].

\section{Ileo-Colectomy}

Patients with terminal ileal CD will require surgical resection for intractable disease or obstructive symptoms in approximately $90 \%$ of cases [31]. The disease usually affects young patients for which a laparotomy can be a significant life event. Laparoscopic ileo-colectomy may be the best initial approach for these patients. Typically the operation involves an initial careful laparoscopic examination of the small and large bowel to identify any other areas of the disease. This is followed by a complete mobilization of the terminal ileal and right colon at least up to the hepatic flexure and mobilization of the small bowel mesentery up to the duodenum. When adequate mobilization has been obtained, the bowel is exteriorized through a 4-cm midline incision that may need to be extended to exteriorize larger terminal ileal phlegmon. We consider the procedure to be 'converted' when this incision is equal to or larger than $10 \mathrm{~cm}$. This provides excellent exposure of the usually thickened mesentery. This is systematically divided using an overlapping Kocher clamp technique and bowel resection is completed. After the ileo-colic anastomosis has been fashioned, this segment of bowel is pushed back into the abdominal cavity and the rest of the small bowel is carefully exteriorized and examined up to the ligament of Treitz. Although 
some series have described a complete intracorporeal operation [2, 32], an extracorporeal resection and anastomosis provide a safer and more rapid handling of the bowel mesentery and the anastomosis, and allow a more reliable examination of the rest of the small bowel with proper palpation of the entire small bowel length. Using this technique, we have identified up to $20 \%$ of patients with unsuspected proximal disease that have required additional surgery (resection or strictureplasty) [9]. Our conversion rate in this consecutive series of 21 patients was found to be only $4.8 \%$. These patients were matched to a similar group of patients undergoing open colectomy. Both, resumption of oral intake (operating day vs. 2nd postoperative day), and resumption of intestinal function ( 2 vs. 4 days), was significantly faster in the laparoscopicresection (LAP) patients. The median LOS was also significantly shorter for the LAP group ( 3 vs. 5 days) and the 30-day readmission rate and complications were overall similar (14 vs. 16\%). In addition, this was the first study to report significantly shorter operative times for the LAP group. There was also an analysis of economic impact in this study. The direct cost was significantly lower in the LAP group (USD 2,547) than in the open group (USD $2,985, \mathrm{p}<0.05)$. The LAP patients also returned to work significantly earlier (4 vs. 6 weeks).

Other series have reported similar results [33, 34]. The Mayo Clinic group reported their experience with 31 consecutive cases and also matched them to a similar group of open cases [35]. The LAP group did significantly better in return of bowel function (2 vs. 4 days), LOS (4 vs. 7 days) and direct costs (USD 8,684 vs. 11,373). Shore et al. [34] have reported equivalent results (table 3). Milsom et al. [36], on the other hand, randomized 60 patients to either LAP ileo-colectomy or to open surgery. Interestingly, although LAP patients had a tendency to do better, there were no significant differences in recovery of gastrointestinal function or LOS. However, LAP patients had better pulmonary function postoperatively (forced vital capacity and forced expiratory volume in $1 \mathrm{~s}$ ) and fewer complications overall.

\section{Laparoscopic Resection for Recurrent or Complicated $C D$}

The feasibility and safety of laparoscopy surgery for recurrent $\mathrm{CD}$, particularly at the ileo-colic anastomosis, has been debated until recently. Similarly, a substantial number of patients with complicated CD (abscess, fistula) have been traditionally denied an initial laparoscopic approach. Arguments for this approach include both the inherent technical challenge and the higher incidence of postoperative septic complications (anastomotic leak, intra-abdominal abscess, or enterocutaneous fistula) that can reach $50 \%$ in patients with multiple additive risk factors (steroid use, low albumin level, presence of abscess, and fistula) [37]. Wu et al. [38] have addressed some of these issues in a study involving 46 patients undergoing LAP ileo-colectomy. Patients were assigned to 3 groups: patients with abscess or phlegmon treated conservatively prior to surgery (group 1, 14 patients); patients with recurrent $\mathrm{CD}$ at the initial ileo-colectomy anastomosis (group 2, 10 patients), and patients with no prior surgery or any other complication (group 3, 22 patients). They also matched these groups to an additional group of patients undergoing open surgery (group 4, 70 patients). The laparoscopic groups (groups 1-3) did better in all aspects than the open group (group 4). Blood loss, operative times (144 vs. $202 \mathrm{~min}$ ), morbidity (6 vs. $21 \%$ ), and LOS (4.4 vs. 7.9 days) were all statistically significant favoring the LAP groups. Conversion rate (21\%) and morbidity (10\%) were higher in patients with recurrent CD disease (group 2), and lowest for the group of patients with sepsis treated preoperatively (group 1). Similar results have been obtained in a more recent series from Japan [39]. In this particular study, 16 patients with recurrent or complicated $\mathrm{CD}$ were compared to 45 patients undergoing LAP resection for the first time. Conversion rates, blood loss, and postoperative outcomes were all similar between groups. The only statistically significant difference was the operative time, which was longer in the group with recurrent disease.

From these studies, and from the experience at this institution, the approach is to offer patients with recurrent or complicated $\mathrm{CD}$ a laparoscopic procedure, knowing that those who require conversion do as well as those undergoing primary open surgery [7]. Those patients, in whom the first operation performed was a laparoscopic ileo-colectomy, may particularly benefit from this repeated approach. It is also preferable to control any intra-abdominal sepsis prior to surgery using interventional radiological support. This may decrease the chance of conversion, as well as septic complications and the risk of diverting enterostomy.

\section{Other Short-Term Outcomes}

A laparoscopic approach may also decrease the incidence of adhesive small bowel obstruction, the incidence of hernias, and cosmesis may improve [15]. In addition, patients may return faster to their normal activities and 
productivity [5]. We performed a study involving a total of 716 patients undergoing either an open colectomy ( 505 patients) or a LAC (211 patients) at the Cleveland Clinic [15]. With a similar follow-up period between groups (open group $=2.42$ years, LAC group $=2.71$ years), the incidence of wound hernia was significantly higher in the open cases $(n=65)$ compared with the LAC group $(n=$ $5, p<0.05)$. The incidence of surgical repair of ventral hernia was also significantly higher among the open group patients ( 28 vs. 4 patients). The incidence of small bowel obstruction was also analyzed. Postoperative small bowel obstruction requiring hospitalization with conservative management occurred significantly less frequently in LAC patients, but the need for surgical intervention for small bowel obstruction was similar between groups. Results from this study also reaffirm the potential economic impact of laparoscopic operations with a potential source of decreased morbidity and significant reduction on the need for readmissions and reoperation.

\section{The Impact of Conversion}

The early series of patients assessing the effectiveness of minimally invasive techniques on patients with IBD failed to demonstrate any clear advantage compared to standard open surgery $[1,2]$. There were also concerns about the possible poorer outcome and higher costs in patients requiring conversion. Although the short-term outcome for patients requiring conversion are worse than those undergoing a successful laparoscopic approach, they should not be worse than patients commencing with standard open surgery. Our group [7] and others [40] have recently addressed the issue of outcome after converted laparoscopic surgery. Fifty-one patients requiring conversion from a laparoscopic approach of 430 consecutive LAC cases were analyzed. There were 12 patients with $\mathrm{CD}$ in the converted group. The converted patients were also matched to a similar group of patients undergoing open colectomy. There were no significant differences in operative times (130 vs. $150 \mathrm{~min}$ ), LOS (5 days for both groups), or direct costs (USD 4,098 vs. 3,666). Outcomes and morbidity (11 vs. $8 \%$ ) were also similar. An important reason for cost containment in this study was the similar operating times between converted and open cases. The ability to perform these complex surgeries in acceptable time frames is increasingly being reported by experienced laparoscopic groups. In addition, in our series, $50 \%$ of the cases were converted during the early stages of the laparoscopic approach. Only $35 \%$ of cases were converted at a later stage of the operation. Early conversion has also been established, an important factor that many impact in the overall reduction of postoperative morbidity and costs by limiting extensive resource utilization. An early judgment to convert a laparoscopic case may determine acceptable clinical and financial outcomes.

\section{Conclusions}

Laparoscopic techniques are increasingly applied to patients with IBD. There is now a more reliable body of evidence supporting the feasibility, safety, cost-effectiveness, and outcomes of patients undergoing a laparoscopic approach. Complication rates appear to be similar and in many cases lower than those seen after standard open surgery. Although ultimate long-term outcomes are still under investigation, preliminary data assessing quality of life and time for re-integration to normal life after surgery are suggestive of a benefit of laparoscopy. As new technology emerges, more patients will benefit from this approach. This new technology must be kept cost-effective, since the costs of this operation can be high. The use of reusable equipment and a standardized approach have proven to decrease costs [41, 42].

Since conversion does not seem to adversely affect outcomes, a policy of starting most cases laparoscopically offers the benefits of LAC to the majority of patients. However, it is strongly advised that the surgeon engaging in this type of operation should also have a substantial level of expertise in both, minimally invasive techniques, and surgical management of patients with IBD. 


\section{References}

1 Reissman P, Salky BA, Pfeifer J, Edye M, Jagelman DG, Wexner SD: Laparoscopic surgery in the management of inflammatory bowel disease. Am J Surg 1996;171:47-50.

-2 Ludwig KA, Milsom JW, Church JM, Fazio VW: Preliminary experience with laparoscopic intestinal surgery for Crohn's disease. Am J Surg 1996;171:52-55

>3 Chen HH, Wexner SD, Weiss EG, Nogueras JJ, Alabaz O, Iroatulam AJ, Nessim A, Joo JS: Laparoscopic colectomy for benign colorectal disease is associated with a significant reduction in disability as compared with laparotomy. Surg Endosc 1998;12:1397-1400.

4 Delaney CP, Kiran RP, Senagore AJ, Brady K, Fazio VW: Case-matched comparison of clinical and financial outcome after laparoscopic or open colorectal surgery. Ann Surg 2003;238: 67-72.

5 Braga M, Vignali A, Gianotti L, Zuliani W, Radaelli G, Gruarin P, Dellabona P, Di Carlo $\mathrm{V}$ : Laparoscopic versus open colorectal surgery: A randomized trial on short-term outcome. Ann Surg 2002;236:759-766.

-6 Ludwig KA, Milsom JW, Garcia-Ruiz A, Fazio VW: Laparoscopic techniques for fecal diversion. Dis Colon Rectum 1996;39:285-288.

7 Casillas S, Delaney CP, Senagore AJ, Brady K, Fazio VW: Does conversion of a laparoscopic colectomy adversely affect patient outcome? Dis Colon Rectum 2004;47:1680-1685.

$\checkmark 8$ Pandya S, Murray JJ, Coller JA, Rusin LC: Laparoscopic colectomy. Indications for conversion to laparotomy. Arch Surg 1999;134: 471-475.

$\checkmark 9$ Duepree HJ, Senagore AJ, Delaney CP, Brady KM, Fazio VW: Advantages of laparoscopic resection for ileocecal Crohn's disease. Dis Colon Rectum 2002;45:605-610.

10 Michelassi F, Finco C: Indications for surgery in inflammatory bowel disease: The surgeon's perspective; in Kirsner JB, Shorter RG (eds): Inflammatory Bowel Disease, ed 4. Baltimore, Williams \& Wilkins, 1995, pp 771-783.

$\checkmark 11$ Hawley PR: Emergency surgery for ulcerative colitis. World J Surg 1988;12:169-173.

-12 Farmer RG, Easley KA, Rankin B: Clinical patterns, natural history and progression of ulcerative colitis: A long-term follow-up of 1,116 patients. Dig Dis Sci 1993;38:1137-1146.

-13 Fleshner PR, Michelassi F, Rubin M, Hanauer SB, Plevy SE, Targan SR: Morbidity of subtotal colectomy in patients with severe ulcerative colitis unresponsive to cyclosporine. Dis Colon Rectum 1995;38:1241-1245.

-14 Whelan RL, Franklin M, Holubar SD, Donahue J, Fowler R, Munger C, Doorman J, Balli JE, Glass J, Gonzalez JJ, Bessler M, Xie H, Treat M: Postoperative cell mediated immune response is better preserved after laparoscopic vs. open colorectal resection in humans. Surg Endosc 2003; 17:972-978.

-15 Duepree HJ, Senagore AJ, Delaney CP, Fazio VW: Does means of access affect the incidence of small bowel obstruction and ventral hernia after bowel resection? Laparoscopy versus laparotomy. J Am Coll Surg 2003;197:177-181.
16 Marcello PW, Milsom JW, Wong SK, Brady K, Goormastic M, Fazio VW: Laparoscopic total colectomy for acute colitis: A case-control study. Dis Colon Rectum 2001;44:1441-1445.

17 Bell RL, Seymour NE: Laparoscopic treatment of fulminant ulcerative colitis. Surg Endosc 2002; 16:1778-1782.

18 Dunker MS, Bemelman WA, Slors JF, van Hogezand RA, Ringers J, Gouma DJ: Laparoscopic-assisted vs. open colectomy for severe acute colitis in patients with inflammatory bowel disease (IBD): A retrospective study in 42 patients. Surg Endosc 2000;14:911-914.

19 Delaney CP, Fazio VW, Remzi FH, Hammel J, Church JM, Hull TL, Senagore AJ, Strong SA, Lavery IC: Prospective, age-related analysis of surgical results, functional outcome, and quality of life after ileal pouch-anal anastomosis. Ann Surg 2003;238:221-228.

20 Kienle P, Weitz J, Benner A, Herfarth C, Schmidt J: Laparoscopically assisted colectomy and ileoanal pouch procedure with and without protective ileostomy. Surg Endosc 2003; 17:716-720.

21 Brown SR, Eu KW, Seow-Choen F: Consecutive series of laparoscopic-assisted vs. minilaparotomy restorative proctocolectomies. Dis Colon Rectum 2001;44:397-400.

22 Dunker MS, Bemelman WA, Slors JF, Van Duijvendijk P, Gouma DJ: Functional outcome, quality of life, body image, and cosmesis in patients after laparoscopic-assisted and conventional restorative proctocolectomy: A comparative study. Dis Colon Rectum 2001;44: 1800-1807.

23 Ky AJ, Sonoda T, Milsom JW: One-stage laparoscopic restorative proctocolectomy: An alternative to the conventional approach? Dis Colon Rectum 2001;45:207-210.

24 Marcello PW, Milsom JW, Wong SK, Hammerhofer KA, Goormastic M, Church JM, Fazio VW: Laparoscopic restorative proctocolectomy: Case-matched comparative study with open restorative proctocolectomy. Dis Colon Rectum 2001;43:604-608.

25 Targarona EM, Garcia E, Rodriguez M, Cerdan G, Balague C, Garriga J, Trias M: Hand assisted laparoscopic surgery. Arch Surg 2003; 138:133-140.

-26 Nakajima K, Lee SW, Cocilovo C, Foglia K, Kim T, Sonoda T, Milsom J: Hand-assisted laparoscopic colorectal surgery using Gelport. Initial experience with a new hand access device. Surg Endosc 2004; 18:102-105.

27 Maartense S, Dunker MS, Slors JF, Cuesta MA, Gouma DJ, van Deventer SJ, van Bodegraven AA, Bemelman WA: Hand-assisted laparoscopic versus open restorative proctocolectomy with ileal pouch anal anastomosis. A randomized trial. Ann Surg 2004;240:984-992.

-28 Delaney CP, Fazio VW, Senagore AJ, Robinson B, Halverson AL, Remzi FH: 'Fast track' postoperative management protocol for patients with high co-morbidity undergoing complex abdominal and pelvic colorectal surgery. Br J Surg 2001;88:1533-1538.
29 Ozuner G, Fazio VW, Lavery IC, Milsom JW, Strong SA: Reoperative rates for Crohn's disease following strictureplasty. Long-term analysis. Dis Colon Rectum 1996;39:1199-1203.

30 Schwandner O, Schiedeck TH, Bruch HP: Stoma creation for fecal diversion: Is the laparoscopic technique appropriate? Int J Colorectal Dis 1998;13:251-255.

31 Kim NK, Senagore AJ, Luchtefeld MA, MacKeigan JM, Mazier WP, Belknap K, Chen SH: Long-term outcome after ileocecal resection for Crohn's disease. Am Surg 1997;63:627633.

32 Dutta BS, Rothenberg JC, Bealer J: Total intracorporeal laparoscopic resection of Crohn's disease. J Pediatr Surg 2003;38:717-719.

33 Benoist S, Panis Y, Beaufour A, Bouhnik Y, Matuchansky C, Valleur P: Laparoscopic ileocecal resection in Crohn's disease: A casematched comparison with open resection. Surg Endosc 2003; 17:814-818.

>34 Shore G, Gonzalez QH, Bondora A, Vickers SM: Laparoscopic vs. conventional ileocolectomy for primary Crohn disease. Arch Surg 2003; 138:76-79.

35 Young-Fadok TM, HallLong K, McConnell EJ, Gomez Rey G, Cabanela RL: Advantages of laparoscopic resection for ileocolic Crohn's disease. Improved outcomes and reduced costs. Surg Endosc 2001;15:450-454.

36 Milsom JW, Hammerhofer KA, Bohm B, Marcello P, Elson P, Fazio VW: Prospective, randomized trial comparing laparoscopic vs. conventional surgery for refractory ileocolic Crohn's disease. Dis Colon Rectum 2001;44: 1-8.

37 Yamamoto T, Allan RN, Keighley MR: Risk factors for intra-abdominal sepsis after surgery in Crohn's disease. Dis Colon Rectum 2000; 43:1141-1145.

38 Wu JS, Birnbaum EH, Kodner IJ, Fry RD, Read TE, Fleshman JW: Laparoscopic-assisted ileocolic resections in patients with Crohn's disease: Are abscesses, phlegmons, or recurrent disease contraindications? Surgery 1997;122: 682-688.

39 Hasegawa H, Watanabe M, Nishibori H, Okabayashi K, Hibi T, Kitajima M: Laparoscopic surgery for recurrent Crohn's disease. Br J Surg 2003;90:970-973.

40 Schwandner O, Schiedeck T, Bruch HP: The role of conversion in laparoscopic colorectal surgery. Do predictive factors exist? Surg Endosc 1999;13:151-156.

41 Senagore AJ, Duepree HJ, Delaney CP, Brady KM, Fazio VW: Results of a standardized technique and postoperative care plan for laparoscopic sigmoid colectomy: A 30-month experience. Dis Colon Rectum 2003;46:503509.

42 Senagore AJ, Duepree HJ, Delaney CP, Dissanaike S, Brady KM, Fazio VW: Cost structure of laparoscopic and open sigmoid colectomy for diverticular disease: Similarities and differences. Dis Colon Rectum 2002;45:485490 . 